\title{
Spontaneous Hemotorax Secondary to Rivaroxabano treatment
}

\section{INTRODUCTION}

Hemothorax corresponds to any pleural effusion with a hematocrit greater than $50 \%$. More oftenly results from trauma or invasive thoracic procedures. Spontaneous hemothorax is rare and may be observed mainly in association with malignancies, pulmonary infarction and spontaneous pneumothorax. Massive hemothorax refers to a blood loss greater than $1500 \mathrm{~mL}^{1-4}$.

Anticoagulation is part of the therapeutic strategy of certain thromboembolic events. Previously the only available anticoagulants were vitamin K antagonists (VKA), with their well-known plasma concentration lability and increased haemorrhagic risk. The emergence of direct oral anticoagulants (DOACs) brought a therapeutic weapon effective as AVK and with a significant reduction in the risk of hemorrhage. Nevertheless some authors argue that hemorrhagic complications in this cases may be worse than those seen with VKA ${ }^{2}$. There are few cases of spontaneous hemothorax secondary to DOACs reported in the literature ${ }^{1,2,4}$.

\section{CLINICAL CASE}

73 year old man, treated with rivaroxaban $20 \mathrm{mg}$ per day due to atrial fibrillation. He came to emergency department complainting of dyspnea and easy fatigue worsened in the last two days. He denied any trauma. Chest radiograph (Figure 1) showed an extensive opacity of the left hemithorax, with contralateral mediastinal deviation. Thoracic CT (Figure 2) revealed the presence of massive left pleural effusion with adjacent lung collapse. A thoracic drain was placed with an immediate outflow of 2 liters of bloody pleural fluid. Analytically, the prothrombin time and the activated partial thromboplastin time was increased, thus vitamin $\mathrm{K}$ and fresh plasma were administered with the purpose of normalizing coagulation times. Due to septation of the effusion, the adopted measures were not enough to completly drain the effusion, so patient was transferred to the thoracic surgery department for surgical drainage of the effusion and pleural descortication. Chest x-ray two months later (Figure 3) shows complete resolution of the effusion.

\section{DISCUSSION}

Spontaneous hemothorax as a complication of anticoagulant therapy with DOACs usually is not an expected occurrence but it should be taken into account by all clinicians when approaching a hypocoagulated patient with de novo pleural effusion ${ }^{1-3}$. To our knowledge there is only one published case of spontaneous hemothorax secondary to rivaroxaban ${ }^{2}$. In the presenting case, chest drain placement and reversion of anticoagulation were not sufficient to solve hemothorax, and the patient underwent video-assisted thoracic surgery for drainage and pleural descortication.

There are no formal indications for resuming oral anticoagulation following an iatrogenic hemorrhagic event. Continuity of the anticoagulant should always be questioned, taking into account the thromboembolic risk versus the risk of further hemorrhage, especially if the hemorrhagic focus is not controlled. It may be licit to stop anticoagulation definitly, replace the initially chosen anticoagulant, or adjust the dose of DOAC according to renal function ${ }^{5}$.
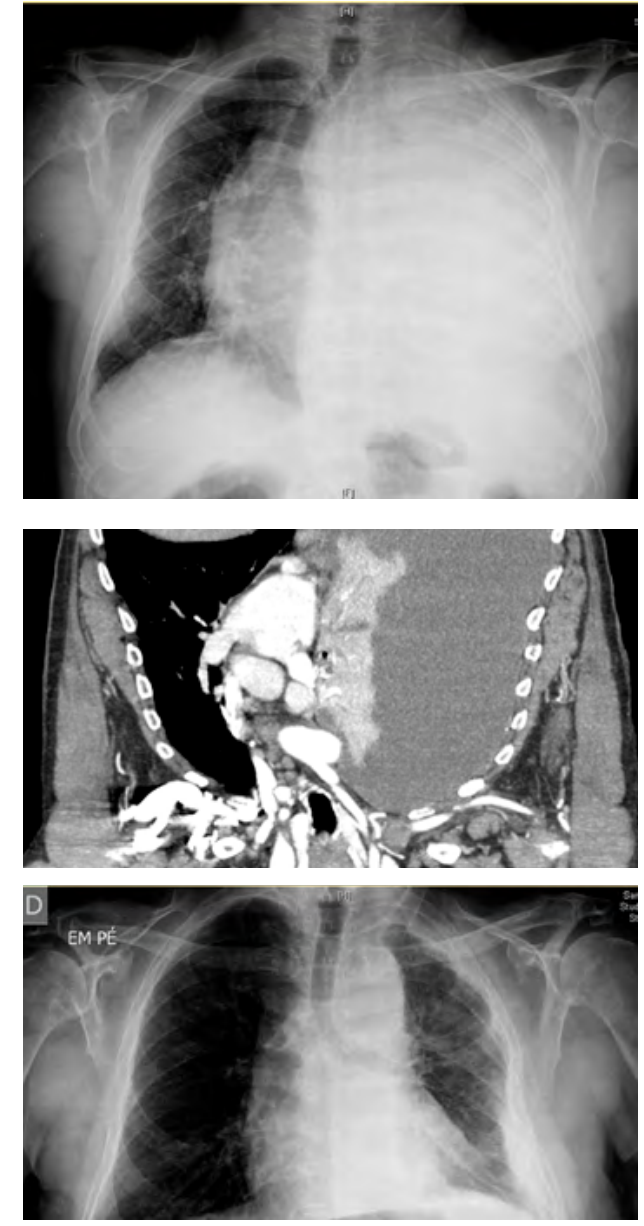

\section{REFERENCES}

1 Hishmeh M, Srivastava P, Lougheide Q, Srinivasan M,Murthy S. Massive Spontaneous Hemothorax as a Complication of Apixaban Treatment. Hindawi Case Reports in Pulmonology. 2018. https://doi.org/10.1155/2108/8735036.

2 Lee $\mathrm{H}$, Jeong Y, Lee J, Lee S. Spontaneous hemothorax as an adverse effect of rivaroxaban treatment. Türk Gög囚üs Kalp Damar Cerrahisi Dergisi 2018;26(2):309311.

3 Huang J, Lin W, Lv D, Yu L, Wu L, Jin H, et al. Dabigatran-Induced Massive Spontaneous Hemothorax. Drug Saf Case Rep. 2017, 22;4(1):12.

4 Akgedik R, Günaydin Z, Bektas 0, Karagöz A, Öztürk H. Spontaneous hemothorax due to dabigatran use in a patient with atrial fibrillation. Clin Respir J. 2017; 11(3):394-396

5 Colantino A, Jaffer A, Brotman D. Resuming anticoagulation after hemorrhage: A practical approach. Cleveland Clinic Journal Of Medicine 2015; 82(4).

\section{DIAGNOSIS}

\section{Spontaneous hemotorax}

\section{Carbalho A, Antunes A \\ Centro Hospitalario de Leiria. Portugal}

Correspondencia: anajocarvalho@gmail.com

Cómo citar este artículo: Carbalho A, Antunes A

Spontaneous Hemotorax Secondary to Rivaroxabano treatment. Galicia Clin 2020; 81 (3): 95

Recibido: 27/01/2019; Aceptado: 19/02/2019 // http://doi.org/10.22546/57/1897 